TERRA. Revista de Desarrollo Local e-ISSN: 2386-9968

Número 7 (2020), 285-291

DOI 10.7203/terra.7.18739

IIDL - Instituto Interuniversitario de Desarrollo Local

\title{
El patrimonio histórico-cultural como \\ herramienta de desarrollo local: Utiel como ejemplo
}

\author{
José Rafael Ponce Iranzo \\ Ldo. en Geografía. Gestor cultural y turístico de Utiel (Valencia, España) \\ estenas@hotmail.com
}

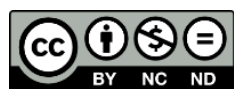

Esta obra se distribuye con la licencia Creative Commons

Reconocimiento-NoComercial-SinObraDerivada 4.0 Internacional 


\section{SECCIÓN EXPERIENCIAS Y BUENAS PRÁCTICAS}

\section{El patrimonio histórico-cultural como herramienta de desarrollo local: Utiel como ejemplo}

Resumen: La recuperación del patrimonio local es una pieza clave para el desarrollo de cualquier municipio, más aún si esté se encuentra afectado por procesos de despoblación. En el caso de Utiel, desde 2015 se ha logrado iniciar toda una serie de acciones destinadas a la recuperación del patrimonio cultural tangible e intangible, gracias a la apuesta por dichos elementos por parte de la administración local y de diversos colectivos sociales. Así, se dispone de un renovado stock de recursos turísticos, como por ejemplo lo son las bodegas del casco histórico, diversas recreaciones culturales e históricas, y distintos edificios y espacios urbanos. Todos estos elementos constituyen un valor único para el proceso de identidad y arraigo que el municipio de Utiel está experimentando en los últimos años, vectores sin duda de un desarrollo territorial mucho más amplio y duradero.

Palabras clave: Turismo, participación cívica, bodegas, identidad local, regeneración urbana.

Recibido: 24 de septiembre de 2020

Devuelto para revisión: -

Aceptado: 21 de octubre de 2020

\section{Referencia / Citation:}

Ponce, J. R. (2020). El patrimonio histórico-cultural como herramienta de desarrollo local: Utiel como ejemplo. TERRA. Revista de Desarrollo Local, (7), 285-291. DOI 10.7203/terra.7.18739 


\section{INTRODUCCIÓN}

La recuperación del patrimonio local es una pieza clave para el desarrollo de un turismo local, de mayor o menor tamaño, que genere oportunidades, sobre todo, en zonas deprimidas o con problemas de despoblación. Otro aspecto de interés en este tipo de intervenciones es el mantenimiento de la cultura más autóctona posible, para lo que debemos evitar caer en la homogeneización que genera la globalización.

En estas páginas apuntamos algunas reflexiones sobre un estudio de cómo era la situación de Utiel en 2015 en materia de patrimonio. No hemos de retrotraernos a décadas pasadas para examinar la evolución de este, sino que hasta hace pocos años en nuestro municipio no se ha optado por la vía patrimonial para posibilitar un desarrollo local.

La política municipal encuentra sus límites temporales en las legislaturas. Esta visión miope y cortoplacista impide, en gran medida, que se puedan llevar a cabo acciones patrimoniales de calado. No obstante, Utiel ha conseguido multiplicar por tres el número de sus visitantes fundamentalmente gracias a dos aspectos. Primero la recuperación patrimonial, y segundo, la participación cívica en la organización y realización de eventos que se han tornado masivos confirmando esta postura. Estamos hablando, concretamente, de "Utiel a la luz de las velas" y las “Jornadas de recreación histórica de la Acción de Utiel” (popularmente conocida en el ámbito local y comarcal como los "Héroes del Tollo"). Otra pieza que ha cobrado una trascendencia importante en diferentes acciones patrimoniales es la Asociación Cultural Serratilla.

\section{RECUPERACIONES PATRIMONIALES REALIZADAS POR LA ADMINISTRACIÓN LOCAL}

La corporación municipal salida de los comicios locales de mayo de 2015, reelegidos en 2019, ha propiciado un aumento considerable de recuperaciones patrimoniales que a continuación se enumeran:

a. Las bodegas subterráneas de Puerta Nueva son un circuito de cinco bodegas intercomunicadas cuyo origen data de los antiguos pasadizos bajomedievales del propio castillo de Utiel. Este recurso surgió tras la recuperación de todos los subterráneos debido a los problemas estructurales que se estaban generando en varias viviendas en la parte superior. Los trabajos consistieron en la consolidación del inmueble, limpieza y mejora de accesos. Por toda la población era conocida la enorme cantidad de bodegas subterráneas que poseía nuestra ciudad, no en vano se calcula que en el centro histórico estaríamos hablando de más de doscientas bodegas y junto con la zona de extramuros, se podría llegar hasta casi el millar. Las primeras con origen medieval al tratarse de unos pasadizos con uso defensivo que se vieron reconvertidas en bodegas, las segundas tras la eclosión vitivinícola de los siglos XVIII y, sobre todo, XIX. Estas bodegas con sus recovecos, profundidades y espacios imposibles son un puzle gigante que hoy en día asombran a quien las visita.

b. Otra bodega recuperada es la perteneciente a la antigua Casa de Ariño, que fue adquirida por el gobierno municipal a principios de siglo para llevar a cabo una ampliación de la casa consistorial. Finalizada dicha ampliación y su reapertura en abril de 2011, la bodega quedó olvidada, pero a partir de 2015, la nueva sensibilidad municipal y el éxito adquirido con el circuito de las bodegas subterráneas de Puerta 
Nueva hizo que esta bodega resucitara en septiembre de 2018, y permitiera hacer disfrutar a todos sus visitantes de un bello arco gótico realizado en sillería, corroborando los consabidos pasadizos medievales que menciona nuestro historiador D. Miguel Ballesteros Viana, que vertebran subterráneamente el antiguo recinto amurallado.

Figura 1. Arco gótico Casa de Ariño

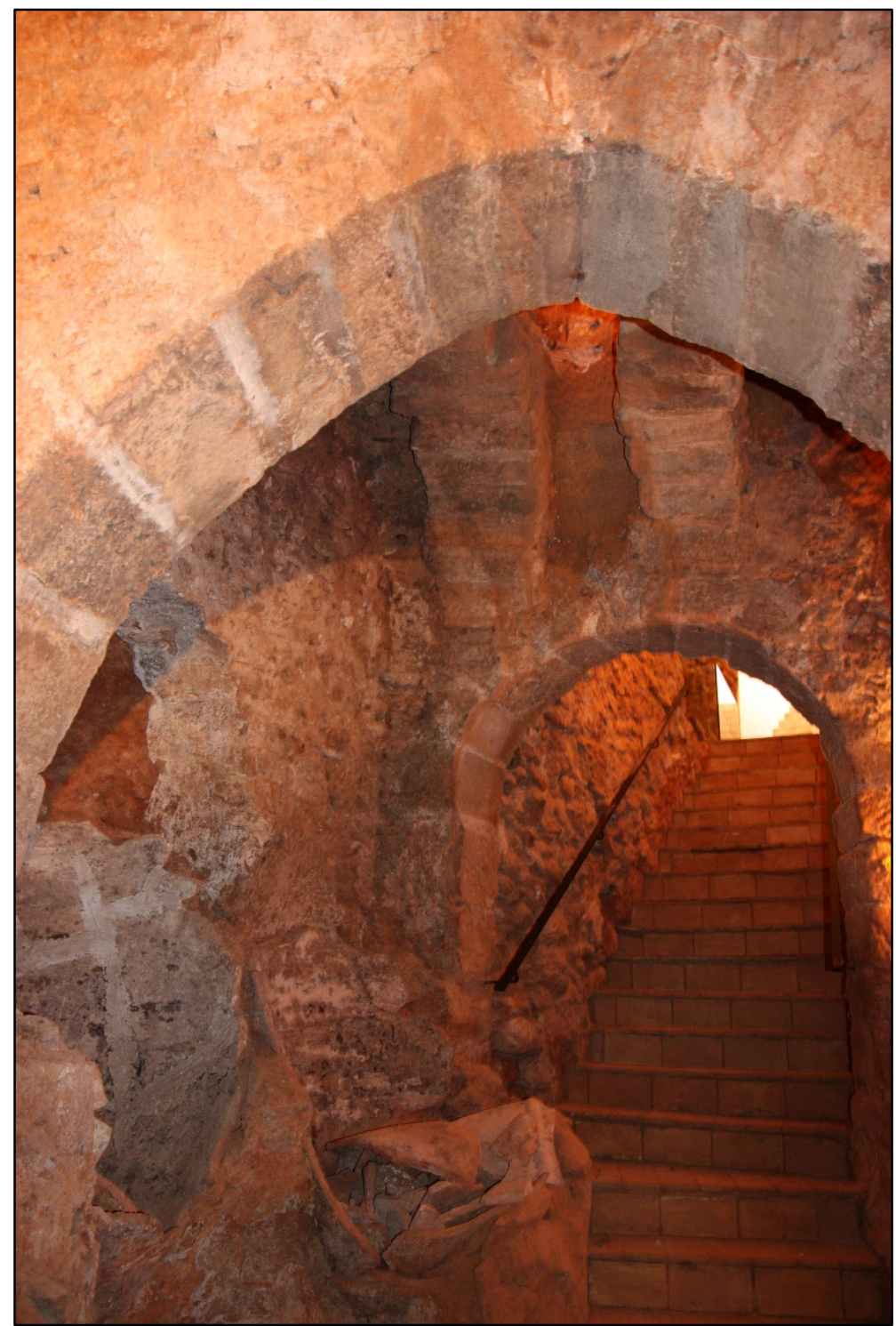

Fuente: José Rafael Ponce Iranzo.

c. Otro ejemplo lo encontramos en la restauración y rehabilitación de la cubierta de la Iglesia Parroquial Ntra. Sra. de la Asunción, un templo de estilo gótico meridional o mediterráneo, en zona de Castilla. Es, sin duda, uno de los bellos y claros ejemplos de este gótico tardío cuya silueta dibuja y recorta el skyline de la Plana de Utiel. Los trabajos que se han realizado, y se siguen realizando, suponen un reto arquitectónico y artístico de envergadura para volver a disfrutarla plenamente.

Hay que destacar el papel del ayuntamiento como impulsor de acciones en la mejora paisajística y ornato público, sobre todo del centro histórico con diversos planes para la 
restauración y adecuación de fachadas para frenar su degradación, o también la creciente peatonalización del centro, haciendo más amigable y sostenible nuestra estancia en estos espacios compartidos.

\section{RECUPERACIONES PATRIMONIALES POR COLECTIVOS CÍVICOS}

El año 2015 supuso una transformación social importante. Hubo una chispa que detonó un proceso que sigue en marcha, por un lado, la creación de la Asociación Cultural Serratilla, la cual comenzó a hacer visitas a bodegas subterráneas de particulares para conocer su estado, potencialidad e incluso como asesoramiento a sus propietarios para su correcta conservación. Por otro lado, la plataforma cívica organizadora del evento "Utiel a la luz de las velas” a través de las redes sociales motivó la unión de un pueblo por lograr un hecho de gran relevancia, y así ocurrió. El éxito se fundamentó en el trabajo colectivo, mostrando con orgullo nuestro patrimonio, de ahí salió uno de nuestros elementos más sobresalientes como son las bodegas subterráneas. Hubo varios propietarios que enseñaron estos espacios con rotundo éxito. El hecho de que todo aquel visitante que podía disfrutar de ellos salía encantado, otorgando el valor que realmente tienen estos espacios, supuso un termómetro de gran importancia para calibrar la potencialidad de estos recursos.

La Asociación Cultural Serratilla ha realizado una importante labor patrimonial tanto tangible como intangible, por ejemplo: recuperación de tres escudos heráldicos; dos fachadas de casas solariegas; dos esculturas de bronce (al historiador D. Miguel Ballesteros Viana y homenaje al tinajero utielano); tres pinturas murales, grabación de dos ediciones de tipo etnológico de memoria oral, paneles con fotografías, exposiciones, conferencias, visitas teatralizadas, visitas tematizadas, concurso de balcones, paseo de los poetas, etc. Multitud de actividades con el fin de dar a conocer el patrimonio utielano en sus múltiples vertientes que han aportado un sello propio al movimiento e inquietudes utielanas.

A raíz del empuje señalado, en el año 2017 llegaron nuevas noticias por la creación de la Asociación Histórico-Cultural Héroes del Tollo, que a través de una efeméride como fue la batalla de la Acción de Utiel durante la Guerra de Independencia en 1812, ha supuesto otro elemento de identidad y valores que se adicionan a los anteriores para reforzar nuestra identidad local. Esta entidad apostó por realizar unas jornadas conmemorativas de la recreación histórica de la Batalla del Tollo, junto con infinidad de actividades lúdicoculturales para ahondar y conocer de forma más cercana este hecho. Simplificando a la máxima expresión se podría denominar: “El pueblo unido jamás será vencido”, este fue el dicho que alentó a nuestros antepasados a espolsarse la presencia militar francesa. A partir de ahí, se despertaron en muchos estamentos socioeconómicos locales la idea de sumar y añadir su ayuda en la culminación de estas jornadas, rescatando aquellos valores de lucha, constancia y tenacidad por lograr el objetivo, pero en esta ocasión brindar un evento masivo que permita exportar el nombre de Utiel turísticamente y generar un ciclo virtuoso de crecimiento asociado a él.

Hay que destacar y poner en valor a multitud de particulares que poseen bodegas subterráneas privadas, una sensibilidad que hay que hacer constar y agradecer como ciudadano en el mantenimiento de forma silenciosa de estos espacios tan arraigados a nuestra identidad y ancestral cultura vinícola. 
Una de las agradables noticias durante este aciago año 2020, se ha tratado de la recuperación del Café Salón Pérez. Una cafetería fechada en 1911 la cual ha visto resurgir gracias a la iniciativa privada, pero esta acción de emprendimiento joven y femenino, apuntala la idea de que la sensibilidad es vital para la supervivencia de los bienes patrimoniales, los cuales per sé tienen historia, vida e identidad propia. Esta nueva apertura, con acertada intervención y puesta en valor, ha supuesto un nuevo elemento de atracción y visitas a este espacio.

Todo este patrimonio, tanto tangible como e intangible, abre y apuntala nuevas vías de recuperación cultural en sus respectivos campos, otorgándoles un valor muy importante localmente.

Figura 2. Bodega subterránea utielana

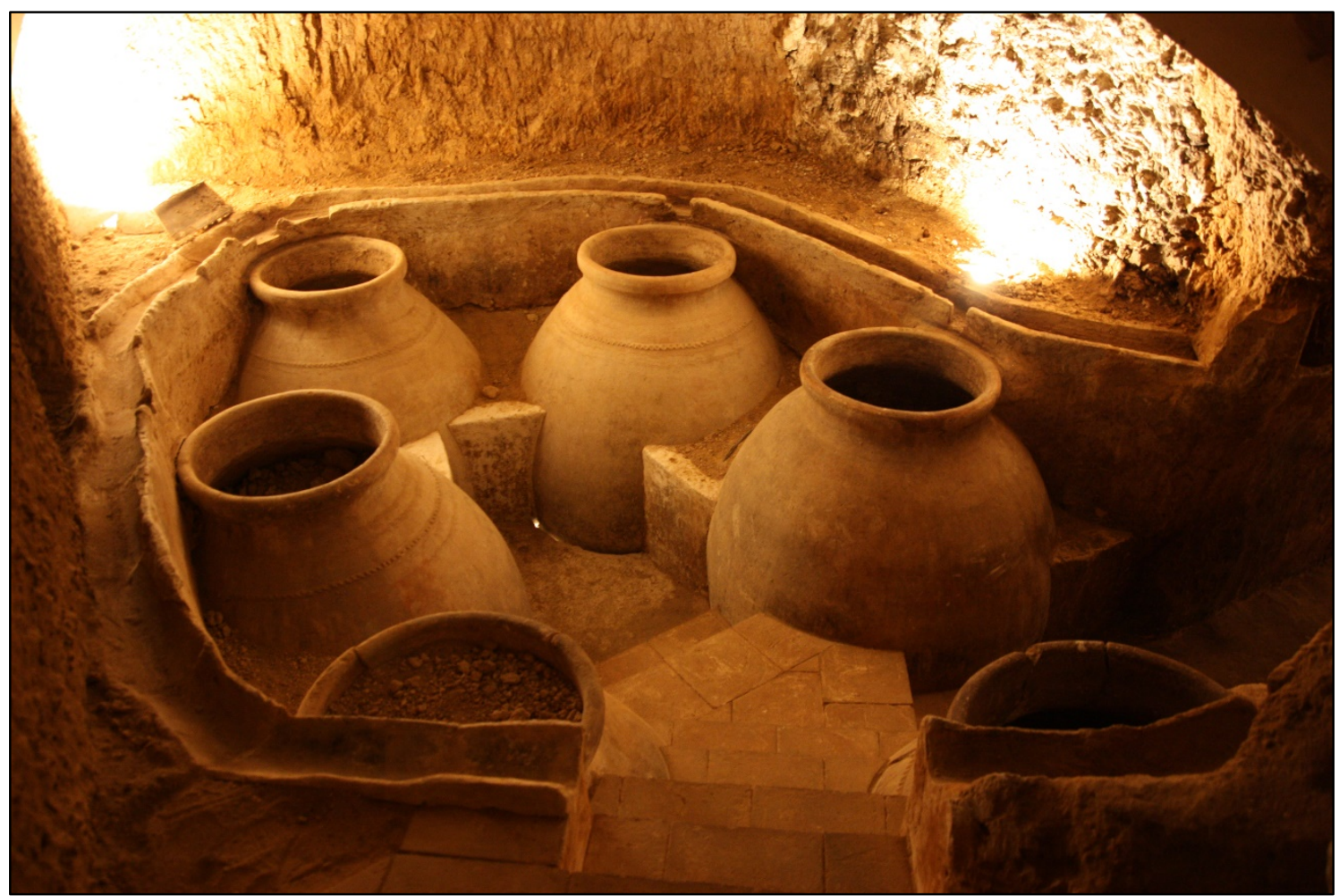

Fuente: José Rafael Ponce Iranzo.

\section{REFLEXIÓN FINAL: OPORTUNIDAD DE REGENERACIÓN URBANA}

Todas estas recuperaciones han supuesto devolver parte de nuestra identidad, no perdida, pero si olvidada de nuevo a sus legítimos dueños, el pueblo. Por ejemplo, tras la guerra civil, las bodegas subterráneas fueron denostadas, pensando, quizá, en que eran símbolo de una cultura atrasada, viejos tiempos. La renovación modernista y la revolución industrial nos trajeron nuevos avances, es una obviedad, pero nuestros antepasados no tuvieron la sensibilidad, en la mayor parte de los casos, para preservar aquel ingente patrimonio, ejemplo extrapolable a buena parte de la geografía española.

Las reformas urbanas, viarias y la reedificación particular de inmuebles trajo consigo la desaparición de muchas bodegas y, en otros casos, su colmatación con escombros, del 
mal el menos. Todos conocíamos el hormiguero que teníamos bajo nuestros pies, una ciudad paralela subterránea, pero las instituciones públicas miraban de reojo estos espacios más como un problema que como una firme opción de futuro. Por lo que la alineación de elementos en 2015 sirvió como palanca para poner en marcha todo lo que hoy en día sigue avanzando.

El rescate patrimonial por parte de la administración municipal, ayudado en parte por otras administraciones, va dirigido a esta regeneración urbana. Son pequeños nodos en los que pivotan las redes más íntimas de un lugar, lo más cercano. Un claro ejemplo lo tenemos en el Café Salón Pérez, como se ha comentado anteriormente, este espacio ha cambiado de gerencia y ha supuesto una transformación para el propio inmueble, así como para el centro histórico. Esta acción, que parece aislada, sirve de acicate para evitar la degradación del centro mejorando su paisaje, entorno y habitabilidad.

En resumen, se ha podido constatar con la recuperación patrimonial que las bodegas subterráneas han supuesto la reafirmación de nuestra identidad, el orgullo de pertenencia y la valoración de todo este patrimonio, generando un vínculo y una empatía hacia esos bienes que le confiere su autenticidad más primigenia, desembocando en su defensa y conservación por toda la colectividad. Es más, el propio equipo de gobierno ha apostado decididamente en la recuperación de todos los espacios municipales que alberguen bodega subterránea, como ocurrió con la bodega del Ayuntamiento, a las que siguieron las bodegas subterráneas de la céntrica y comercial Plaza Puerta del Sol, y el refugio antiaéreo de la Guerra Civil, el cual tiene también otra bodega.

En definitiva, las acciones patrimoniales municipales, las asociativas, las cívicas o las empresariales son puntos latentes que bombean fuerzas centrífugas y centrípetas a partes iguales. Primero pisando el freno a la degradación de los centros históricos, haciéndolos más habitables y convirtiéndolos en desinhibidores para, segundo, detener su despoblación y la percepción negativa que en algunos aspectos suscitan para, finalmente, poder generar así dinámicas positivas de crecimiento y oportunidades de desarrollo para la economía local.
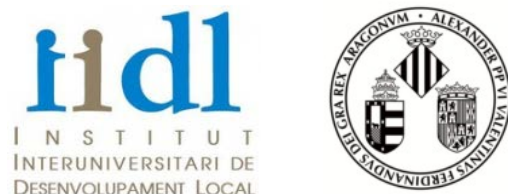

VNIVERSITAT (E) VALÈNCIA 